\title{
Safety of bronchodilator reversibility test in elderly subjects: a prospective study
}

\author{
Anna Dor-Wojnarowska1, Anna Parużyńska², Aleksandra Kulczak², Marta Majewska-Pulsakowska1, \\ Małgorzata Szymala-Pędzik², Zbigniew Machaj², Małgorzata Sobieszczańska², Małgorzata Poręba ${ }^{3}$
}

${ }^{1}$ Department and Clinic of Internal Medicine and Allergology, Wroclaw Medical University, Wroclaw, Poland ${ }^{2}$ Department and Clinic of Geriatrics, Wroclaw Medical University, Wroclaw, Poland

${ }^{3}$ Department of Pathophysiology, Wroclaw Medical University, Wroclaw, Poland

Adv Dermatol Allergol 2021; XXXVIII (2): 256-261 DOI: https://doi.org/10.5114/ada.2020.92515

\begin{abstract}
Introduction: The reversibility test measures an increase in ventilation parameters after the administration of $400 \mu \mathrm{g}$ of a short-acting $\beta$-agonist (SABA). It is worth noting that a typical dosage, applied as a rescue medicine for bronchospastic dyspnoea, is significantly less, i.e., 100-200 $\mu$ g.

Aim: To assess the effects of inhaled $400 \mu \mathrm{g}$ fenoterol (in the bronchodilator reversibility test) on the heart rate and the development of tachyarrhythmias in subjects aged 65 and above.

Material and methods: A total of 53 subjects (45 women) aged 77; 68-82 (median; interquartile range) in stable clinical condition were included in the study. Data including medical history, physical examinations, blood biochemistry, chest X-ray, 12-lead electrocardiogram, 24-hour Holter ECG monitoring, bronchodilator test, and echocardiography were obtained. During the Holter ECG monitoring, the bronchodilator test using $400 \mu \mathrm{g}$ fenoterol (Berotec pMDI) was performed.

Results: A slight but statistically significant $(p=0.02)$ increase in heart rate from 71 to 75 per min (median) was noted after the administration of fenoterol. No statistically significant differences were found in the number of extrasystolic beats of either supraventricular $(p=0.42)$ or ventricular origin $(p=0.50)$. In addition, the subjects did not show any potentially dangerous arrhythmias or significant signs of coronary artery disease. However, there was a significant increase in the number of supraventricular beats in the subjects who were not taking $\beta$-blockers. Conclusions: The use of $400 \mu \mathrm{g}$ fenoterol in a bronchodilator reversibility test in elderly subjects does not entail any significant cardiovascular risk.
\end{abstract}

Key words: 24-hour Holter ECG monitoring, bronchodilator test, elderly subjects.

\section{Introduction}

The bronchodilator reversibility test is one of the most common diagnostic tests performed in diseases with symptomatic dyspnoea. The test is also a recommended method for determining the reversibility of obstruction in asthma and severity classification of chronic obstructive pulmonary disease (COPD). The reversibility test measures an increase in forced expiratory volume in $1 \mathrm{~s}\left(\mathrm{FEV}_{1}\right)$ and forced vital capacity (FVC) parameters after the administration of a bronchodilator (short-acting $\beta$-agonist - SABA). The dosage of $400 \mu \mathrm{g}$ of a SABA, such as salbutamol or fenoterol, is recommended by the GOLD, the GINA, and the ATS/ERS guidelines $[1,2]$.
A standard dosage, however, applied as a rescue medicine in bronchospastic dyspnoea is 100-200 $\mu \mathrm{g}$.

Numerous studies have shown a significant chronotropic and dromotropic influence of SABA on the heart. Insulander et al. found that salbutamol infusion caused significant electrophysiological changes at all levels of the conduction system of the heart, which was most evident in the atrioventricular (AV) node [3]. It is worth noting that even in healthy adults, inhalation of $200 \mu \mathrm{g}$ of salbutamol causes a significantly faster heart rate and a decline in peripheral vascular resistance [4]. Burggraaf et al. [5] demonstrated that in subjects suffering from hypoxemia, salbutamol inhalation not only caused a faster heart rate but also triggered vasodilation, which could

Address for correspondence: Anna Dor-Wojnarowska MD, PhD, Department of Internal Diseases and Allergology, Wroclaw Medical University, 66 M. Skłodowskiej-Curie St, 50-369 Wroclaw, Poland, phone: +48 71784 25 21, e-mail: dor_anna@yahoo.co.uk Received: 22.09.2019, accepted: 17.10.2019. 
lead to pulmonary shunt and decrease in diastolic pressure [5].

Previous studies have reported the frequent incidence of unstable angina pectoris and myocardial infarction (MI) in subjects taking both short- and longacting $\beta$-adrenergic medicines [6-9]. Lee et al. [6] found that the estimated risk of myocardial infarction among new users of $\beta$-adrenergics was significantly elevated $(O R=3.2)$ especially in those with cardiovascular disease $(\mathrm{OR}=7.3)$ compared with subjects who had never received a $\beta$-agonist, which can be partially attributed to the impact of $\beta$-adrenergic drugs on heart rate and the occurrence of arrhythmias [6].

The reports of increased risk of acute coronary syndromes in subjects inhaling $\beta$-adrenergic drugs [6-8] raise concerns about the safe use of 400 - $\mu$ g short-acting, $\beta$-adrenergic drugs in the bronchodilator test in elderly subjects. Until now, the risk of significant tachyarrhythmias that can lead to MI with the use of such a dosage of SABA in elderly subjects with concomitant heart diseases has not been established.

\section{Aim}

The primary goal of this study was to examine the relationship between inhaled $\beta$-agonist used in the bronchodilator test in older subjects and the risk of cardiovascular events including tachyarrhythmia.

\section{Material and methods}

\section{Study population}

For this study, we recruited 53 non-smoking subjects (45 women) aged 77; 68-82 who were admitted to the geriatric department of Wroclaw Medical University. The subjects were hospitalised during 2017-2019 for a comprehensive geriatric assessment. They were all in a stable clinical state. Subjects suffering from respiratory diseases and/or taking inhalation drugs were excluded from the study. Assessment of medical history, physical examinations, blood biochemistry, chest X-ray, 12-lead electrocardiogram, 24-hour Holter monitoring, bronchodilator test, and echocardiography were performed.

The detailed characteristics of the participants are presented in Table 1.

The research was approved by the Bioethical Committee at Wroclaw Medical University (reference number 417/2016). All subjects provided written informed consent.

\section{Bronchodilator test}

The bronchodilator test was conducted between 11 and 12 a.m. on the same day when Holter monitoring began. Before and during the test, the subjects did not perform any physical activities and did not smoke cigarettes.
Spirometry was performed before and 15 min after fenoterol inhalation using a Master Scope spirometer (Erich Jaeger $\mathrm{GmbH}$, Wurzburg, Germany) according to the recommendations of ATS/ERS [2]. Particular emphasis was placed on the test repeatability and acceptability criteria [2]. In the test, a dose of $400 \mu \mathrm{g}$ of fenoterol (Berotec made by Boehringer Ingelheim) was administered (4 puffs of $100 \mu \mathrm{g}$ ) by an MDI inhaler under the supervision of the certified staff. The GLI2012 reference values were used to interpret the results. The bronchodilator test results were presented in percentages of the predicted and initial values.

\section{4-hour Holter ECG monitoring}

24-hour Holter ECG monitoring was performed using a 12-lead device produced by Lifecard CF (Reynolds Medical, Hertford UK). The obtained data were processed using specific software, and the reports were prepared by an experienced cardiologist. In this study, we compared the heart rate and the amount of ventricular and supraventricular extrasystoles (VE and SVE) an hour before and after the bronchodilator test.

\section{Echocardiography examination}

We used a two-dimensional, M-mode cardiovascular ultrasound system (Siemens Acuson X300). The examination was conducted in the left lateral decubitus position. All echocardiographic examinations were performed by an experienced cardiologist.

\section{Statistical analysis}

The data analysis was undertaken using Statistica 13 software (StatSoft). The Shapiro-Wilk test was performed to investigate the normal distribution of the sample. As the studied parameters were not normally distributed, non-parametric tests were used. The data were expressed as median (Me) and the interquartile

Table 1. Demographic data

\begin{tabular}{lccc}
\hline Parameters & Median & $\begin{array}{c}\text { Interquartile } \\
\text { range 25-75\% }\end{array}$ & $\mathbf{N}$ \\
\hline Age [years] & 77 & $68-82$ & 53 \\
\hline Sex, $n$ (female/male) & & & $45 / 8$ \\
\hline BNP [pg/ml] & 77 & $27-115$ & 53 \\
\hline $\begin{array}{l}\text { Sodium concentration } \\
\text { [mEq/l] }\end{array}$ & 141 & $139-142$ & 53 \\
\hline $\begin{array}{l}\text { Potassium concentration } \\
\text { [mEq/l] }\end{array}$ & 4.2 & $4.0-4.6$ & 53 \\
\hline $\begin{array}{l}\text { Systolic blood pressure } \\
\text { [mm Hg] }\end{array}$ & 130 & $120-142$ & 53 \\
\hline $\begin{array}{l}\text { Diastolic blood pressure } \\
\text { [mm Hg] }\end{array}$ & 75 & $70-80$ & 53 \\
\hline$N-$ number of examined patients. & & & \\
\hline
\end{tabular}


Table 2. Patients' comorbidity and medicines used

\begin{tabular}{lc}
\hline Parameter & $\boldsymbol{N}(\%)$ \\
\hline Comorbidity: & \\
\hline Hypertension & $44(83)$ \\
\hline Diabetes & $14(26)$ \\
\hline CAD (coronary artery disease) & $19(36)$ \\
\hline Past history of MI & $6(11)$ \\
\hline Past history of stroke & $22(41)$ \\
\hline Mitral valve insufficiency & $45(84)$ \\
\hline Tricuspid valve insufficiency & $43(81)$ \\
\hline Atrium enlargement & $23(43)$ \\
\hline Diastolic heart failure & $38(71)$ \\
\hline Interventricular septal hypertrophy & $30(56)$ \\
\hline Atrial fibrillation & $6(11)$ \\
\hline Chronic kidney disease & $3(5,5)$ \\
\hline Medicines: & $11(20)$ \\
\hline Diuretics & $13(24)$ \\
\hline Calcium channel blockers & $19(36)$ \\
\hline Beta-blockers & $22(41)$ \\
\hline ACE inhibitors & \\
\hline
\end{tabular}

$N$-number of examined patients, \% - percent of examined patients.

Table 3. Heart ultrasound examination results

\begin{tabular}{|c|c|c|c|}
\hline Parameter & Median & $\begin{array}{l}\text { Interquartile } \\
\text { range } \\
25-75 \%\end{array}$ & $N(\%)$ \\
\hline EF & 65 & $60-65$ & \\
\hline Mitral valve insufficiency & & & $45(84)$ \\
\hline Tricuspid valve insufficiency & & & $43(81)$ \\
\hline Atrium enlargement & & & $23(43)$ \\
\hline Diastolic heart failure & & & $38(71)$ \\
\hline $\begin{array}{l}\text { Interventricular septal } \\
\text { hypertrophy }\end{array}$ & & & $30(56)$ \\
\hline Aorta [mm] & 33 & $32-35$ & \\
\hline Left atrium [mm] & 40 & $38-43$ & \\
\hline $\begin{array}{l}\text { Left ventricular diameter } \\
\text { diastole }[\mathrm{mm}]\end{array}$ & 46 & $44-50$ & \\
\hline $\begin{array}{l}\text { Left ventricular diameter } \\
\text { systole }[\mathrm{mm}]\end{array}$ & 28 & $25-32$ & \\
\hline Septum [mm] & 12 & $10-13$ & \\
\hline Posterior wall [mm] & 10 & $9-10$ & \\
\hline Right ventricle [mm] & 26 & $25-28$ & \\
\hline
\end{tabular}

$N$-number of examined patients, \% - percent of examined patients.

range $25-75 \%$. The Kolmogorov-Smirnov or Friedman's ANOVA test was performed to compare two independent samples. For dependent samples, the Wilcoxon or McNemar test was performed. The correlation between the variables was analysed by means of the Spearman test. A value of $p<0.05$ was considered as statistically significant for all tests.

\section{Results}

A group of 53 subjects (45 women) aged 77: 68-82 took part in the study. The subjects had not suffered from any respiratory tract diseases and had not used any inhalation medicines, including $\beta$-adrenergic drugs. The most common health problems in that population were hypertension (83\% of the subjects) and coronary artery disease (CAD) (36\%). In addition, $41 \%$ of the subjects were stroke survivors (Table 2). A total of $36 \%$ of the subjects used $\beta$-blockers and $13 \%$ used calcium channel blockers (Table 2).

\section{Echocardiography}

The echocardiography revealed a normal heart ejection fraction (EF) in all the study subjects (median 65; 60-65\%). Diastolic dysfunction characteristics were found in $71 \%$ of the subjects. The majority of the subjects had confirmed heart valve dysfunctions. The most commonly occurring dysfunctions were mitral valve insufficiency (84\%) and tricuspid valve insufficiency (81\%). The other parameters are shown in Table 3.

\section{Spirometry}

The initial (before inhalation) spirometry showed a moderately severe obstruction in only 1 patient ( $\mathrm{FEV}_{1}$ $-50 \%$ of predicted value). The other subjects did not have any pulmonary dysfunction. FEV median was $97 \%$ (85-106\%) of the predicted value and FVC was 104\% (68-149\%) of the predicted value. After the drug inhalation, FEV improved by $5 \%(-17 \% ; 22 \%)$, as compared to the initial value (Table 4).

\section{4-hour Holter electrocardiographic monitoring}

The Holter ECG monitoring readings taken an hour before and after the bronchodilator test were compared. In 6 (11\%) subjects, atrial fibrillation was found, while the other subjects had the sinus rhythm. A slight but statistically significant increase in heart rate from $71 / \mathrm{min}$ to $75 /$ min (median) was noted after the administration of fenoterol.

In $39 \%$ of the subjects, premature ventricular beats before drug administration were found. After fenoterol inhalation, such an abnormality occurred in $32 \%$ of the subjects $(p<0.001)$. Premature supraventricular beats were found in $72 \%$ of the subjects before the bronchodilator reversibility test, and after drug inhalation $(p=0.01)$ in $79 \%$. However, when the number of ventricular and supraventricular beats during those periods was compared, no statistically significant differences were found $(p=0.42)$ (Table 5). 
Because $36 \%$ of the studied population was treated by $\beta$-blockers, which would influence the final results, we analysed them separately. Table 5 shows that the $\beta$-blocker group had a lower heart rate before $(p<0.001)$ and after fenoterol inhalation $(p<0.001)$ compared with the non-treated subjects. We found a significant increase in heart rate $(p=0.009)$ and the number of subjects with supraventricular beats in the $\beta$-blocker group $(p=0.02)$. No potentially dangerous arrhythmias or signs of CAD were found in the subjects.

In the non-treated group of subjects, we found a statistically significant increase in the number of subjects with supraventricular beats $(p<0.001)$ and a larger increase in heart rate after the inhalation of fenoterol $(p=0.04)$ than we observed in $\beta$-blocker-treated subjects (Figure 1).

No statistically significant impact of the SABA on the occurrence of tachycardia or other arrhythmias was found.

\section{Discussion}

The aim of our study was to investigate whether $400 \mu \mathrm{g}$ of fenoterol, used in the bronchodilator test, would trigger an increase in heart rate and the development of tachyarrhythmias that could contribute to acute coronary syndrome in elderly subjects.
Table 4. Spirometry test results before and after $400 \mu \mathrm{g}$ fenoterol inhalation

\begin{tabular}{lcc}
\hline Parameter & Median & $\begin{array}{c}\text { Interquartile } \\
\text { range (25-75\%) }\end{array}$ \\
\hline FEV $_{1}$ (before inhalation) (\% pred) & 97 & $85-106$ \\
\hline FVC (before inhalation) (\% pred) & 104 & $89-117$ \\
\hline FEV (after inhalation) (\% pred) & 103 & $89-121$ \\
\hline FVC (after inhalation) (\% pred) & 109 & $95-126$ \\
\hline
\end{tabular}

FVC\% pred-forced vital capacity \% predicted, FEV $\%$ pred-forced expiratory volume in $15 \%$ predicted.

Until now, much attention has been focused on the effects of SABA on the heart conduction system and peripheral vascular system [4, 10-12]. Numerous studies have shown a noticeable chronotropic effect of inhaled and intravenous drugs in the healthy population $[10,12,13]$, young people suffering from asthma [2,14], and children [11, 15] treated for the exacerbation of asthma or COPD [16-19]. Lee et al. found an increased risk of tachyarrhythmias in subjects using long-acting $\beta$-adrenergic and parasympatholytic drugs [20]. Tachycardia was caused not only by the direct effect on $\beta$-adrenergic receptors of the heart but also by indirect activation of receptors causing vessels' dilation and reaction of the vagus nerve [12, 21]. This effect is linked to a greater risk of an acute cardiovascular incident in the population

Table 5. Frequency of occurrence of additional ventricular and supraventricular beats in patients $(N=53)$

\begin{tabular}{|c|c|c|c|c|c|c|c|}
\hline \multirow[t]{2}{*}{ Parameter } & \multicolumn{3}{|c|}{ Before the test } & \multicolumn{3}{|c|}{ After the test } & \multirow[t]{2}{*}{$P$-value } \\
\hline & MED & $\begin{array}{l}\text { Interquartile } \\
\text { range }\end{array}$ & $N(\%)$ & MED & $\begin{array}{l}\text { Interquartile } \\
\text { range }\end{array}$ & $N(\%)$ & \\
\hline \multicolumn{8}{|l|}{ All studied patients: } \\
\hline Heart rate [beats/min] & 71 & $64-81$ & & 75 & $69-83$ & & 0.020 \\
\hline VES per hour & 0 & $0-2$ & & 0 & $0-2$ & & 0.502 \\
\hline Occurrence of VES & & & $21(39)$ & & & $17(32)$ & 0.000 \\
\hline SVES per hour & 3 & $0-34$ & & 3 & $1-58$ & & 0.424 \\
\hline Occurrence of SVES & & & $38(72)$ & & & $42(79)$ & 0.010 \\
\hline \multicolumn{8}{|c|}{ Patients treated with $\beta$-blockers: } \\
\hline Heart rate [beats/min] & 67 & $62-79$ & & 71 & $69-81$ & & 0.009 \\
\hline VES per hour & 0 & $0-1$ & & 0 & $0-1$ & & 0.371 \\
\hline Occurrence of VES & & & $6(31)$ & & & $6(31)$ & 0.080 \\
\hline SVES per hour & 4 & $1-30$ & & 2 & $0-14$ & & 0.464 \\
\hline Occurrence of SVES & & & $15(84)$ & & & $14(74)$ & 0.024 \\
\hline \multicolumn{8}{|c|}{ Patients who were not treated with $\beta$-blockers: } \\
\hline Heart rate [beats/min] & 73 & $65-82$ & & 78 & $69-84$ & & 0.05 \\
\hline VES per hour & 0 & $0-2$ & & 0 & $0-3$ & & 0.484 \\
\hline Occurrence of VES & & & $13(42)$ & & & $11(35)$ & 0.12 \\
\hline SVES per hour & 2 & $0-34$ & & 2 & $1-58$ & & 0.799 \\
\hline Occurrence of SVES & & & $13(42)$ & & & $22(70)$ & \\
\hline
\end{tabular}

VES - ventricular beats, SVES - supraventricular beats, $N$-number of examined patients, $\%$ - percent of examined patients. 
A

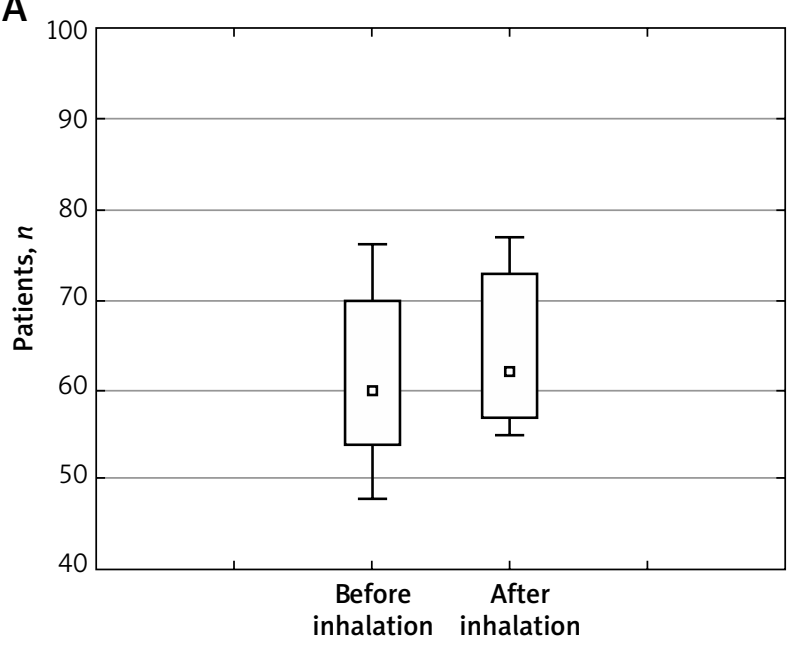

B

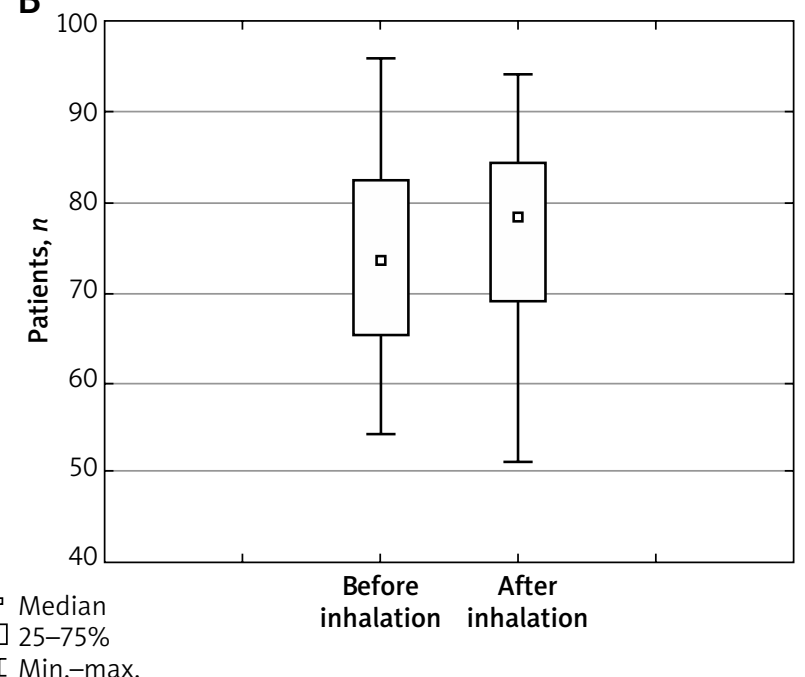

Figure 1. Heart rate before and after inhalation of fenoterol in patients treated (A) and not treated (B) with $\beta$-blockers

of patients treated with inhalation drugs, especially at the beginning of a therapy $[6,7,9]$.

Because of these findings, a dosage of $400 \mu \mathrm{g}$ of salbutamol or fenoterol used in the bronchodilator test in elderly subjects suffering from circulatory diseases and particularly CAD raises concerns. We conducted the $\beta$-adrenergic test in elderly subjects without respiratory tract diseases who had not used $\beta$-adrenergic drugs before. In this study, using 24-hour Holter ECG monitoring, we found that a slight post-inhalator increase in heart rate $(p=0.006)$ did not trigger the exacerbation of electrocardiographic signs of heart ischemia. Compared to baseline after the inhalation of fenoterol, no significant increase in the number of ventricular or supraventricular extrasystoles was observed in these subjects. However, after the drug inhalation, supraventricular extrasystoles occurred more often and ventricular premature beats less often in the studied population. No potentially dangerous arrhythmias were found among the examined subjects. However, we observed a significant increase in heart rate and the number of supraventricular beats in the non- $\beta$-blocker-treated group. Therefore, it can be concluded that using $400 \mu \mathrm{g}$ of the short-acting $\beta$-adrenergic drug in elderly subjects is safe, but it should be performed with caution.

This study has some limitations. The group consisted of elderly subjects in a good general condition, and none of the subjects showed signs of heart failure, electrolyte imbalance, or respiratory impairments. The studies that have shown an increased risk of acute coronary syndrome [6, $7,9]$ investigated populations with confirmed obstructive lung disease (asthma or COPD). This means that apart from the drug itself, other factors, such as exacerbation of the underlying disease, hypoxemia, electrolyte imbalance and other comorbidities, had an additional effect on the studied subjects. Future studies on the current topic are, therefore, recommended.

\section{Conclusions}

We observed only a slight but statistically significant increase in heart rate in subjects after the administration of $400 \mu \mathrm{g}$ of inhaled fenoterol. However, there was a significant increase in the number of supraventricular beats in the subjects who had not taken $\beta$-blockers.

The study has shown that the older subjects did not experience potentially dangerous tachyarrhythmias after the administration of fenoterol. In subjects not treated by $\beta$-blockers or with concomitant serious heart disease, the bronchodilator test should be performed with caution.

\section{Acknowledgments}

The publication was prepared under a project financed from funds granted by the Ministry of Science and Higher Education in the "Regional Initiative of Excellence" programme for the years 2019-2022, project number 016/ RID/2018/19, the amount of funding 11998121.30 PLN.

This work was supported by Wroclaw Medical University [grant number ST.310.16.089].

\section{Conflict of interest}

Anna Dor-Wojnarowska received financial support for attending the symposium EAACI 2018 from the company Chesi. Other authors declare no conflict of interest.

\section{References}

1. Global Initiative for asthma. Global Strategy for Asthma Management and Prevention 2018. https://ginasthma.org/ gina-reports/. 
2. Pellegrino R, Viegi G, Brusasco V, et al. Interpretative strategies for lung function tests. Eur Respir J 2005; 26: 948-68.

3. Insulander P, Juhlin-Dannfelt A, Freyschuss U, Vallin H. Electrophysiologic effects of salbutamol, a beta2-selective agonist. J Cardiovasc Electrophysiol 2004; 15: 316-22.

4. Cekici L, Valipour A, Kohansal R, Burghuber OC. Short-term effects of inhaled salbutamol on autonomic cardiovascular control in healthy subjects: a placebo-controlled study. $\mathrm{Br}$ J Clin Pharmacol 2009; 67: 394-402.

5. Burggraaf J, Westendorp RG, in't Veen JC, et al. Cardiovascular side effects of inhaled salbutamol in hypoxic asthmatic patients. Thorax 2001; 56: 567-9.

6. Lee CH, Choi S, Jang EJ, et al. Inhaled bronchodilators and acute myocardial infarction: a nested case-control study. Sci Rep 2017; 7: 17915.

7. Neville E, Corris PA, Vivian J, et al. Nebulised salbutamol and angina. Br Med J 1982; 285: 796-7.

8. Au DH, Lemaitre RN, Curtis JR, et al. The risk of myocardial infarction associated with inhaled beta-adrenoceptor agonists. Am J Respir Crit Care Med 2000; 161: 827-30.

9. Wang MT, Liou JT, Lin CW, et al. Association of cardiovascular risk with inhaled long-acting bronchodilators in patients with chronic obstructive pulmonary disease: a nested casecontrol study. JAMA Intern Med 2018; 178: 229-38.

10. Edgell H, Moore LE, Chung C, et al. Short-term cardiovascular and autonomic effects of inhaled salbutamol. Respir Physiol Neurobiol 2016; 231: 14-20.

11. Sarnaik SM, Saladino RA, Manole M, et al. Diastolic hypotension is an unrecognized risk factor for beta-agonist-associated myocardial injury in children with asthma. Pediatr Crit Care Med 2013; 14: e273-9.

12. Snyder EM, Wong EC, Foxx-Lupo WT, et al. Effects of an inhaled beta2-agonist on cardiovascular function and sympathetic activity in healthy subjects. Pharmacotherapy 2011; 31: 748-56.

13. Beloka SP, Janssen C, Woff E, et al. Effects of beta2-adrenergic stimulation on exercise capacity in normal subjects. Eur J Appl Physiol 2011; 111: 2239-47.

14. Eryonucu B, Uzun K, Güler N, Bilge M. Comparison of the acute effects of salbutamol and terbutaline on heart rate variability in adult asthmatic patients. Eur Respir J 2001; 17: 863-7.

15. Bio LL, Willey VJ, Poon CY. Comparison of levalbuterol and racemic albuterol based on cardiac adverse effects in children. J Pediatr Pharmacol Ther 2011; 16: 191-8.

16. Virk MK, Hotz J, Khemani RG, et al. Change in oxygen consumption following inhalation of albuterol in comparison with levalbuterol in healthy adult volunteers. Lung 2017; 195: 233-9.

17. Brunetti L, Poiani G, Dhanaliwala F, et al. Clinical outcomes and treatment cost comparison of levalbuterol versus albuterol in hospitalized adults with chronic obstructive pulmonary disease or asthma. Am J Health Syst Pharm 2015; 72 : 1026-35.

18. Zulkarneev R, Zagidullin N, Abdrahmanova G, et al. Ivabradine prevents heart rate acceleration in patients with chronic obstructive pulmonary disease and coronary heart disease after salbutamol inhalation. Pharmaceuticals 2012; 5: 398-404.

19. Lam S, Chen J. Changes in heart rate associated with nebulized racemic albuterol and levalbuterol in intensive care patients. Am J Health Syst Pharm 2003; 60: 1971-5.

20. Lee CH, Choi S, Jang EJ, et al. Inhaled bronchodilators and the risk of tachyarrhythmias. Int J Cardiol 2015; 190: 133-9.
21. Fowler SJ, Lipworth BJ. Pharmacokinetics and systemic beta2-adrenoceptor-mediated responses to inhaled salbutamol. Br J Clin Pharmacol 2001; 51: 359-62. 